\section{Debatendo alguns desafios da Reforma Psiquiátrica brasileira}

Discussing some challenges

facing Brazilian psychiatric reform

\section{Ana Marta Lobosque ${ }^{1}$}

Já no resumo de seu texto Ana Pitta interroga: estaria ameaçada ou não a vitalidade da Reforma brasileira? Para avançar em tal indagação seria preciso, a meu ver, caracterizar de onde vem e em que consiste essa vitalidade. Ela se relaciona, con sidero, com o tipo de questões com as quais lida mos e com a maneira ousada pela qual as formu lamos: as relativas à experiência da loucura.

Tal experiência, não consideramos apenas, ou essencialmente, como perturbações cerebrais ou psicológicas daqueles que a vivenciam, mas como um risco da condição humana: um certo impas se da dimensão ficcional que necessariamente constitui nossa forma de pensar e de conhecer. Inventamos o pensamento, a linguagem... e eis que, de repente, essa invenção deixa de ser social mente partilhada para assumir o caráter solitá rio e intransmissível daquilo que a psicopatolo gia denomina como neologismo, delírio, estereo tipia. Ou, num outro exemplo, consumimos as chamadas substâncias psicoativas, muitas vezes como forma agradável de laço social, e eis que o seu uso, sobretudo daquelas mais nocivas, tor na se para alguns uma ruptura dos laços que nos ligam às pessoas e à vida, isolados como res tos nas ruas.

Participar do movimento antimanicomial sig nifica compreender que para lidar com essas situ ações limite são inúteis as estratégias autoritárias ou coercitivas. Por mais danosas que sejam, por mais que revelem nossa exposição a algo que nos ultrapassa e nos domina, revelam algo em nós que não obedece, que não se dobra a nenhuma ordem ou imperativo, alguma coisa que nos reti ra da condição de "corpos dóceis e úteis" (para usar a expressão de Foucault), apontando algu ma coisa de incurável que nos habita. Desde as instituições totais até a guerra às drogas, passan do pelas várias abordagens tecnicistas, nada dis so oferece saída, nem cria possibilidades de laços e de vida. Há que provocar desejos, endereçar con vites, tecer redes e a este fim se destinam , assim compreendo os princípios, as ações e os equipa mentos que compõem a Reforma Psiquiátrica.

Feitas estas considerações iniciais, inicio o diá logo com o texto de Ana Pitta abordando os três pontos que me parecem essenciais para a vitali dade da Reforma. São eles: a concepção das redes de cuidado; as questões relativas à formação; a relação da Reforma com os movimentos sociais.

\section{A concepção das redes de cuidado}

A clareza conceitual na concepção das redes parece me essencial ao êxito na sua implantação. Para cuidar em liberdade é preciso que essas re des sejam descentralizadas, ou seja: por um lado, não devem organizar se em torno de um dispo sitivo centralizador, qualquer que seja; por ou tro, devem estender se na tessitura do espaço social, tornando se cada vez menos técnicas e menos sanitarizadas.

Elenco a seguir alguns dos principais desa fios para uma rede assim concebida.

Um deles é o desafio da atenção à crise. Ana Pitta observa, com pertinência: não podemos acolher os usuários em situação de urgência, se os nossos serviços fecham às 17 horas. Contu do, há que declarar em alto e bom som o nosso propósito efetivo de extinção dos hospitais psi quiátricos e instituições afins. Eles não fazem parte da rede tal como a concebemos: não vale enca minhar lhes, de forma implícita ou não, aqueles casos que "não damos conta". Tal constatação nos leva, por um lado, à importante questão da implantação dos CAPS III (Centros de Atenção Psicossocial), cuja escassez em território brasilei ro é um dos pontos fracos da nossa Reforma. Leva nos, por outro lado, a pensar que a crise, dependendo de sua gravidade, do contexto só cio familiar, do vínculo entre usuário e equipe, pode também ser acolhida em diferentes pontos da rede: não só nos CAPS, mas na atenção bási ca, nos centros de convivência, e assim por dian te. Seja como for, importa sustentar o que se se gue: não há Reforma Psiquiátrica efetiva sem garantia de atendimento à crise.

Outro desafio fundamental é a inclusão da atenção básica em nossa rede de cuidados. Ela representa o espaço mais próximo do usuário no âmbito do território. Cumpre assegurar o direito de todo cidadão sem excluir, é claro, o portador de sofrimento mental ao acolhimen to, ao vínculo e à responsabilização do cuidado com sua equipe da unidade básica. Aqui, a par
${ }^{1}$ Residência Multiprofissional em Saúde Mental, Escola de Saúde Pública de Minas Gerais. anamarta.lo@oi.com.br 
ceria com os colegas do PSF (Programa de Saúde na Família) é fundamental, só se faz pela oferta de formação elementar na área, de matriciamen to pelas equipes de Saúde Mental, de retaguarda pelos CAPS quando se requerem cuidados inten sivos, e assim por diante. Um índice expressivo da presença real da Reforma num território dado se expressa quando o portador de sofrimento mental é, como qualquer outro usuário, acolhi do e escutado pela equipe do PSF ao chegar à unidade básica, e encaminhado devidamente, se necessário, à equipe de Saúde Mental. E, vice e versa, quando o seu acompanhamento pela Saú de Mental, seja na própria unidade básica seja no CAPS, não desresponsabiliza o PSF dos cuida dos que lhe cabe oferecer.

Enfim, cito mais um desafio: aquele dos pas sos "além da saúde", para usar uma expressão da Linha Guia de Saúde Mental de Minas Ge rais. Trata se daquelas ações e equipamentos que não são, sensu strictu, sanitários, mostrando se, todavia, essenciais à saúde. Incluem se aqui as moradias concebidas não como serviços de Saúde, mas sim como casas onde vivem pessoas, precisando ou não de algum grau de proteção, mas jamais de tutela. Mais ainda, porém, são de importância decisiva os Centros de Convivência, os Grupos de Produção Solidária, que desenham na cidade novos recortes e aberturas para o trân sito do portador de sofrimento mental entre nós. A geração de renda, aliás, embora possível e ne cessária, não pode ser o objetivo primeiro: as trocas em jogo não são primordialmente aque las de compra e venda do mercado. Trata se, sim, de produzir objetos e coisas mas objetos e coi sas cuja função precípua é a de tecer laços: laços afetivos, amorosos, políticos, sociais, em contí nuo entrelace com aqueles da cidade. Finalmen te, incluem se nos passos "além da saúde" as pro paladas, porém pouco executadas, parcerias in tersetoriais, com a educação, a justiça, os direitos humanos e a assistência social.

Um breve comentário, de passagem: para o enfrentamento desses e de outros desafios, não se pode atribuir ao CAPS o papel de organizador do território. O CAPS, por motivos diversos, tem certa tendência de fechar se em si mesmo, que só se pode combater quando o convocamos desde fora para o âmbito mais amplo da rede. A orga nização do território não lhe pode ser delegada pelo gestor sob pena de colocá lo num lugar cen tralizador que o captura: cumpre convidar os diferentes pontos da rede como atores da terri torialização que buscamos.

\section{A formação}

A questão da formação, também menciona da no texto de Ana Pitta, parece me requerer um importante acento. Sabemos da profunda distân cia ainda existente entre a Reforma Psiquiátrica e a universidade. A formação permanente é indis pensável aos gestores, aos trabalhadores e aos usuários: na sua ausência, permanecem impossi bilitados de problematizar as questões advindas das inusitadas práticas que exercem. As lacunas não preenchidas pelas formações básica e perma nente acabam por ser mal e mal supridas no âm bito da pós graduação, impedindo que se consti tua um nível realmente avançado de formação.

Ora, convém examinar estes problemas da formação, dentre outros aspectos, à luz do esta do de produção teórica no âmbito do saber que se pretende central na Saúde Mental: o saber psi quiátrico. Pode se dizer que a psiquiatria se de bate num impasse: por um lado, sofre as exigên cias de cientificidade que lhe são feitas enquanto especialidade médica; por outro, sem jamais con seguir atendê las, procura persuadir se de que o faz. Leia se, por exemplo, um capítulo sobre a transmissão genética dos distúrbios psíquicos em qualquer moderno manual: de fato, são escru pulosamente científicas as exigências para expli car a hereditariedade de determinado distúrbio. Ora, essas exigências requerem uma definição rigorosa do distúrbio que se pretende pesquisar e a classificação dos distúrbios quanto mais se esforça para favorecer a clara e inequívoca iden tificação de cada um deles, tanto mais lineariza e falsifica os critérios que a deveriam propiciar.

Essa condição atual da disciplina psiquiátri ca tem um elemento muito perigoso para a Re forma, se nos deixarmos embalar por seu ideal de cientificidade. Mas tem também, paradoxal mente, um elemento positivo: ao percebemos quão infecundo é o impasse em questão, afirma se a necessidade de prosseguir a formação em Saúde Mental numa direção bem diversa. Aquilo que aprendemos nos serviços abertos, os múlti plos saberes que neles se produzem, tem uma realidade clínica e uma pertinência política indu bitáveis, reconhecida pelos atores envolvidos: tra ta se de ajudá los a sustentar a dimensão de ver dade que aí encontram, articulando marcos con ceituais e campos de prática.

\section{Reforma Psiquiátrica e movimento social}

Seria muito difícil para qualquer pessoa vin culada à Reforma negar a importância do mo 
vimento social em sua construção. O texto de Ana Pitta aponta, ao longo das últimas décadas, vários eventos, encontros, manifestações, produzidas por tal movimento ou a ele vinculadas. Não creio, entretanto, que reine entre nós o mesmo consen so a respeito do que seja um movimento social.

Em primeiro lugar, um movimento social, que se expressa em manifestações da mais viva es pontaneidade, exige todavia, para produzi las, uma militância rigorosa, que envolve trabalho, disciplina e organização. Convenhamos, afinal não nasce ex nihilo a marcha dos usuários em Brasília ocorrida em 2009, assegurando a IV Conferência Nacional de Saúde Mental.

Essa militância requer um espaço de atuação singular, com a lógica que lhe é própria, que dife re da política, por melhor que seja, feita no âm bito das instituições. No movimento social, a re lação entre os técnicos, os usuários e os familia res, exterior ao espaço dos serviços e indepen dente das condições ditadas por eles, não é ape nas a do cuidado, nem a do afeto: trata se de um laço propriamente político, cuja construção de mocrática é um desafio tão grande quanto ines quecível é o seu aprendizado.

Um movimento social, mesmo quando par ceiro do poder público e de suas instituições, deve sustentar a independência arduamente construí da fora deles. Ora, tal independência é facilmente confundida com radicalismos ou implicâncias, quando não compreendemos a sua necessidade. E qual é tal necessidade, afinal? Consiste justa mente em preservar uma radicalidade, entendi da como aquilo que está na raiz, na razão de ser de uma luta; de não poder perder de vista princí pios, posições, e até mesmo certas palavras, que sustentam a nossa concepção da loucura como experiência humana e a defesa de uma outra for ma de convívio com ela. Por exemplo, afasta mo nos do movimento social quando aceitamos, embora veladamente, a presença do hospital psi quiátrico, seja na clínica, seja no ensino; ou quan do preferimos não usar o termo "antimanicomi al”, sob a alegação de que estaria ultrapassado; ou quando não escutamos como se torna muito maior o relevo da fala de um usuário ou familiar quando parte do diálogo construído cotidiana mente com seus pares.

Seria ridículo exigir que todos aqueles que de fendem a Reforma Psiquiátrica sejam militantes de movimentos sociais organizados, ou que não possam criticar erros eventuais desses movimen tos. Contudo, seríamos ignorantes ao menospre zá los. Cumpre reconhecer, levando em conta as dificuldades que enfrentam, e valorizando as con quistas que promovem, sua importância funda mental. Afinal, não nasce de outra fonte senão esta a dos movimentos sociais a poderosa vi talidade da Reforma Psiquiátrica brasileira! 